\title{
Cementless total hip arthroplasty for three different degrees of hip involved secondary to ankylosing spondylitis: an analysis of 195 hips
}

\author{
Ping Mou ${ }^{1}$, Hua Li ${ }^{2}$, An-Jing Chen ${ }^{1}$, Zheng Ji ${ }^{3}$, Xin-Yi Dai ${ }^{3}$ and Zong-Ke Zhou ${ }^{1 *}$ (1)
}

\begin{abstract}
Background: Hip involved secondary to ankylosis spondylitis (AS) had a huge influence on hip function. Cementless total hip arthroplasty (THA) can improve hip function. However, no previous study compared the outcomes of THA for AS patients with three different degrees of hip involvement.

Methods: The 195 hips were retrospectively analyzed and divided into non-ankylosed group (group A, 94 hips), fibrous ankylosed group (group B, 49 hips), and bony ankylosed group (group C, 52 hips). postoperative range of motion (ROM), harris hip scores (HHS), the short-form 12 health survey (SF-12), length of stay (LOS), cost, radiological assessments, and complications were compared.
\end{abstract}

Results: The follow-up time was (79.4 \pm 29.5$)$ months for group A, (80.6 \pm 28.9$)$ months for group B, and (79.1 \pm 28.9$)$ months for group $C(P=0.966)$. Group $A$ had the best postoperative hip ROM $(P<0.001)$, while group $A$ and $B$ can realize better HHS than group $C(P<0.001)$. The three groups had similar SF-12 postoperatively. For group A, LOS and cost for unilateral procedure were the least than that for group $B$ and $C(P=0.003$ and $P=0.001)$. Similar radiological assessments were achieved for three groups. 1 hip in group $A$ encountered delay union of wound. 1 hip in group $C$ encountered delay union of wound and dislocation and another patient encountered femoral fracture intraoperatively. 12 hips (12.8\%) in group A, 6 hips (12.2\%) in group B, and 6 hips (11.5\%) in group C encountered asymptomatic heterotopic ossification $(P=0.977)$.

Conclusion: For AS patients with hip involvement, THA can improve hip ROM and function. THA for the non-ankylosed hip can realize the better hip function and postoperative ROM than ankylosed hip.

Keywords: Total hip arthroplasty, Ankylosing spondylitis, Ankylosed hip, Non-ankylosed hip, Range of motion

\section{Introduction}

Ankylosing spondylitis (AS) diagnosed using the modified New York criteria [1] is an inflammatory disease affecting the axial spine and peripheral joints, characterized by low back pain, limited range of motion (ROM) of the lumbar spine and hip joint involved, and resulting in

\footnotetext{
*Correspondence: zhouzongke@scu.edu.com

${ }^{1}$ Department of Orthopedics, Orthopedic Research Institute, West China Hospital, Sichuan University, \#37 Guoxue Road, Chengdu 610041, People's Republic of China

Full list of author information is available at the end of the article
}

functional impairment and decreased quality of life [2]. The diagnosis of AS based on the modified New York criteria requires sacroiliitis on imaging, low back pain and stiffness for $>3$ months, limited lumbar spine ROM, and/ or limited chest expansion. And the prevalence of AS in China is $0.22 \%$ and more common in males $(0.36 \%)$ than in females $(0.09 \%)$ but no significant regional difference [3]. Hips involved occupied $30-50 \%$ of patients diagnosed with AS [4]. The involved hips present with progressive pain, bone deformity, and gradual loss of hip ROM along with disease advance. Flexion contracture of hip and spinal kyphosis were the two most common original author(s) and the source, provide a link to the Creative Commons licence, and indicate if changes were made. The images or other third party material in this article are included in the article's Creative Commons licence, unless indicated otherwise in a credit line to the material. If material is not included in the article's Creative Commons licence and your intended use is not permitted by statutory regulation or exceeds the permitted use, you will need to obtain permission directly from the copyright holder. To view a copy of this licence, visit http://creativecommons.org/licenses/by/4.0/. The Creative Commons Public Domain Dedication waiver (http://creativecommons.org/publicdomain/zero/1.0/) applies to the data made available in this article, unless otherwise stated in a credit line to the data. 
characteristics for AS patients [5]. The mobility of the hip is conducive to compensatory for kyphosis, correction of limp, and functional improvement [6]. So, ROM restoration for AS patients is crucial.

The literature has reported that AS is diagnosed correctly for 7-10 years after patients experience various symptoms. Effective treatment may be delayed for the patients until correct diagnosis [7, 8] and the hips may progress to various degrees of involvement and present different degrees of ROM loss. Additionally, AS was pathologically characterized by inflammation of tendon insertion [2]. And different degrees of lesions caused by AS showed various changes of soft tissue, which may result in different influences on hip function even if total hip arthroplasty (THA) was performed. Currently, according to the different severities of hip lesions, three different lesions can emerge including non-ankylosed hip [6, 9, 10], fibrous ankylosed hip [11-13], and bony ankylosed hip [10-12, 14, 15], which were defined as no total loss of hip ROM, no continuous bony trabecula passing through the hip joint on X-ray with $0^{\circ}$ hip ROM, and continuous bony trabecula bridging the hip joint on X-ray with $0^{\circ}$ hip ROM. Moreover, different severities of lesions indicated different technological demands and operational invasions. The scholars [13] considered that degree of bone deformity and the level of soft tissue contracture were two decisive contributors to hip ROM. They [13] also stressed that rehabilitation training according to different deformities was related to postoperative ROM. Also, other scholars [6] concluded poor postoperative ROM in patients with preoperative bony ankylosis than that with stiff cases. Currently, literature has reported the clinical and radiographic outcomes of THA for AS patients. But they have different limitations such as small sample size [10-12, 14], short-term follow-up [5, 14], various implanted prostheses or fixation techniques $[9,15]$, and confounded results of bony and fibrous ankylosed hips $[11,12,16]$. No one study compared the outcomes of THA for three different degrees of hip involvement secondary to AS.

So, we retrospectively analyzed the AS patients in our joint center with different degrees of hip involvement and reported the effectiveness of THA for these patients. It was hypothesized that for AS patients with hip involvement, THA can improve hip function and realize good radiographic assessments for AS patients. And the differences may be found in three groups on clinical and radiographic evaluation.

\section{Materials and methods}

\section{Ethics statement}

Data were collected by retrospective review of our database from January 2010 to December 2017. Study approval was obtained from the Clinical Trials and Biomedical Ethics Committee of West China Hospital (ID: 2012-268). All experiments were performed following relevant guidelines and regulations. This study was conducted according to the Declaration of Helsinki. The data included patient demographics, clinical measurements, radiological assessments, and complications.

\section{Patients}

The inclusion criteria: patients diagnosed with AS and performed cementless THA; hip involved secondary to AS; no total loss of hip ROM regarded as non-ankylosed group (group A); no continuous bony trabecula passing through the hip joint on X-ray with $0^{\circ}$ hip ROM regarded as fibrous ankylosed group (group B); continuous bony trabecula passing through the hip joint on X-ray with $0^{\circ}$ hip ROM regarded as bony ankylosed group (group C). The exclusion criteria: patients performed THA for other reasons; hip ankylosis caused by other reasons.

\section{Surgical procedures}

After general anesthesia, all THA was performed using a posterolateral approach in the lateral decubitus position. The femoral neck was identified according to the lesser trochanter after total capsulectomy and cutting off the external rotators. For the non-ankylosed hip, the joint space can be distinguished clearly. Hip dislocation, osteotomy of the femoral head, and acetabular reaming can be done like general THA regularly after removal of osteophytes and scar. But for the fibrous and bony ankylosed hip, femoral neck osteotomy was conducted without hip dislocation due to total loss of hip ROM. Take care to avoid damage to the greater trochanter and posterior acetabulum. The acetabulum was deepened and widened in the medial direction using hemispherical reamers with gradual increases in diameters. The counterrotation technique was used to avoid over-reaming of the osteoporotic acetabulum. And the original joint plane was located by the foveal soft tissue and incomplete gray ossifying cartilage. The optimal cup size and cup inclination of the acetabulum prosthesis were identified by the preoperative project and intraoperative fluoroscopy. And the anteversion of the cup was confirmed with the indication of transverse acetabular ligament and the long axis of the body. The press-fit technique was conducted to insert the cementless acetabular implants. If the initial stability was not satisfactory, additional screws would be used to fix the cup before inserting the liner.

Sequentially larger reamers were used to enlarge the canal until the diaphyseal cortex was reached. Then femoral trial prosthesis was inserted to correct the leg length discrepancy (LLD), check the stability in all directions, and optimize the femoral offset. The cementless femoral 
prosthesis and femoral head were inserted. The hip stability and ROM were checked again to ensure postoperative mobility. At last, the external rotator muscles were restored in situ and the drainage was selected according to the time of operation and blood loss before incision suturing. If the hip can't be passively abducted more than $15^{\circ}$, adductor tenotomy would be performed. All prostheses were used the same brand (DePuy Orthopadics, Marsaw IN) and friction couples were selected based on the patients' financial status and activity levels.

\section{Perioperative regimen}

Isometric exercises and positive motion were encouraged to conduct in bed immediately after recovering from anesthesia. Prophylactic intravenous antibiotics and low-molecular-weight heparin (LMWH) were systematically conducted. Half-dose LMWH (enoxaparin, $0.2 \mathrm{ml}, 2000 \mathrm{IU})$ was routinely scheduled subcutaneously $6 \mathrm{~h}$ postoperatively, and a full dose (enoxaparin, $0.4 \mathrm{ml}, 4000 \mathrm{IU})$ was given at 24-h intervals until discharge. After discharge, $10 \mathrm{mg}$ of rivaroxaban was used orally for 10 days. Non-steroidal anti-inflammatory drugs were used to relieve pain and reduce the chance of heterotopic ossification ( $\mathrm{HO}$ ) for 2 weeks. For unbearable postoperative pain, additional painkillers by intravenous or intramuscular injection were added. The drainage tube was removed within $24 \mathrm{~h}$. Routine clinical follow-up visits were conducted at 2 weeks, 4 weeks, 12 weeks, and 6 months after surgery and annually.

\section{Clinical measurements}

Clinical details were recorded including hip ROM, Harris Hip Scores (HHS) preoperatively and postoperatively, Additionally, satisfaction levels and the short-form 12 health survey (SF-12) score postoperatively were also evaluated. The special ruler was used to measure the hip flexion, extension, and abduction positively in the supine position. HHS (the total score was 100) was used to evaluate the function of the hip [17] and rated as excellent (90-100), good (80-89), fair $(70-79)$, and poor $(<70)$. Patients' satisfaction was evaluated using a self-administered four-category scale (very satisfied, satisfied, somewhat unsatisfied, and unsatisfied). SF-12 score including physical component summary (PCS) and mental component summary (MCS) can act as a measurement reflecting the life quality recently [18]. Additionally, from our database, we collected the data including patient demographics at the time of surgery, component information, length of stay (LOS), and total hospital expense (THE). LOS was calculated how many nights the patients stayed in the hospital. THE was calculated how much Chinese yuan (¥) the patients spent on THA in hospital and presented in Chinese yuan ( $¥)$; currently, $1 ¥=0.154$ United States dollars (USD, \$).

\section{Radiological assessments}

Standard anteroposterior (AP) radiograph was obtained preoperatively and postoperatively. The assessments included the inclination of the cup (IC), the femoral offset (FO), the difference of bilateral FO, and LLD. The angle crossed by the horizontal line connecting both teardrops and line through the longest diameter of the elliptical opening of the acetabular cup rim was recorded and regarded as IC [11]. If the teardrops were unrecognizable or the pelvis was asymmetric, we firstly bisected the sacrum with a vertical line A and secondly drawn a perpendicular line B to line A [11]. So, line B can be regarded as a horizontal line. FO was defined as the vertical distance from the center of the femoral head to the ipsilateral anatomical femoral axis [19]. LLD was assessed by the standardized-trochanteric method to avoid the influence of pelvic obliquity and femoral inclination on the radiographs [20]. The standardized-trochanteric method required the vertical distance from the inter-teardrop line to the center of rotation and the femoral vertical distance (center of rotation to the lesser trochanter) reference to the femoral anatomical axis. So, the unilateral distance was defined as the difference between the two vertical distances. And LLD was equal to the difference between the two unilateral distances. Figure 1 has shown the detailed process of measurement.

\section{Complications}

The complications were recorded including early-onset and late-onset complications. The possible early-onset complications collected from the database consisted of dislocation, wound complications, infection, intraoperative fracture, deep venous thrombosis, pulmonary embolism, and nerve palsy. Additionally, the possible late-onset complications consisted of dislocation, HO, osteolysis, and aseptic loosening. According to Brooker classification [21], we analyzed and classified the degrees of HO. Osteolysis was defined as cystic or scalloped lesions with a diameter of more than $2 \mathrm{~mm}$ on radiograph $[22,23]$. According to the criteria of DeLee [24], the acetabular component was defined as loose if a complete radiolucent line was thicker than $2 \mathrm{~mm}$ at the bone-implant interface or migration of the component. Besides, the femoral implant stability was evaluated according to Engh et al. [25], the stem was considered loose if subsidence more than $2 \mathrm{~mm}$ or angular shift of the stem more than $2^{\circ}$.

For the clinical measurement, radiological assessment, and complication evaluation, two investigators (HL and AJC) who did not know the group allocation and were not involved in the surgery individually performed the 


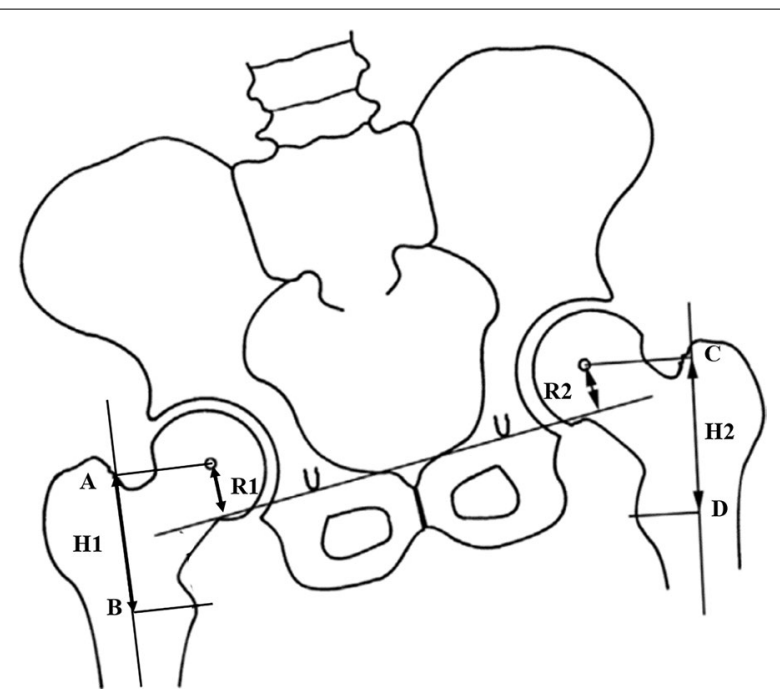

Fig. 1 Diagram showing a standardized-trochanteric method to assess leg-length discrepancy. R1 and R2 are the vertical distance from the bilateral center of rotation to the inter-teardrop line. Line $A B$ and line $C D$ are the anatomical axes of the femurs. Point $A$ and point $C$ are the perpendicular intersections from the center of rotation to the femoral anatomical axis. Point $B$ and point $D$ are the perpendicular intersections from the tip of the lesser trochanter to the femoral anatomical axis. $\mathrm{H} 1$ and $\mathrm{H} 2$ are equal to $A B$ and $C D$, respectively. Leg-length discrepancy $=(H 1-\mathrm{R} 1)-\left(H_{2}-\mathrm{R} 2\right)$

measurements. If no consensus was got, the investigator (PM) who also did not know the group allocation confirmed the final results.

\section{Statistical analysis}

Continuous data are presented as the mean and standard deviation (SD) or as the median with the interquartile range. Categorical data are shown as the number and percentage. A 1-way analysis of variance (ANOVA) with post-hoc Tukey test was used for normally distributed continuous variables, and the Kruskal-Wallis analysis with post-hoc Nemenyi test was used for skewed continuous variables. Chi-square or Fisher tests were applied for categorical variables. Significance was set at the level of $P<0.05$.

\section{Results}

Ultimately, we included 69 patients (94 hips) with the mean age of $(42.2 \pm 13.8)$ years old for group A, 40 patients (49 hips) with the mean age of $(40.6 \pm 13.3)$ years old for group B, and 28 patients (52 hips) with the mean age of $(38.8 \pm 8.5)$ years old for group $C(P=0.311)$. Among the patients, 11 patients from group $A, 2$ patients from group $\mathrm{B}$, and 12 patients from group $\mathrm{C}$ were performed bilateral THA synchronously. And 14 patients from group A, 7 patients from group B, and 12 patients from group $\mathrm{C}$ were performed bilateral THA sequentially.
And the others were performed unilateral THA. The positive rate of human leukocyte antigen B27 (HLA B27) was $84.1 \%$ for group A, $87.5 \%$ for group B, and $85.7 \%$ for group $\mathrm{C}(P=0.885)$. Friction couples including ceramicon-ceramic bearing $(\mathrm{CoC})$ and ceramic-on-polyethylene bearing $(\mathrm{CoP})$ were identical for all hips. The $\mathrm{CoC}$ bearing was used 64 hips (68.1\%) for group A, 41 hips (83.7\%) for group $\mathrm{B}$, and 37 hips $(71.2 \%)$ for group $\mathrm{C}$, while $\mathrm{CoP}$ bearing was used 30 hips (31.9\%) for group A, 8 hips (16.3\%) for group B, and 15 hips $(28.8 \%)$ for group C $(P=0.132)$. Table 1 showed the demographics of three study groups.

\section{Clinical outcomes}

The mean postoperative follow-up was (79.4 \pm 29.5$)$ months for group A, $(80.6 \pm 28.9)$ months for group $\mathrm{B}$, and $(79.1 \pm 28.9)$ months for group $\mathrm{C}$, respectively $(P=0.966)$. The average HHS increased from $(31.5 \pm 4.3)$ to $(89.1 \pm 3.2)$ for group $\mathrm{A},(30.9 \pm 3.8)$ to $(88.2 \pm 3.2)$ for group B, and $(30.9 \pm 5.0)$ to $(83.7 \pm 2.3)$ for group C. Postoperative HHS of group A and group B was higher than that of group $C(P<0.001)$, while no difference was found between group A and group B $(P=0.078)$. The HHS of all patients from three groups was rated as poor preoperatively, while more than $90 \%$ of hips were rated as excellent or good at the latest follow-up. For group A, the flectionextension ROM was $(72.2 \pm 27.5)^{\circ}$. Moreover, significant difference was also found in preoperative flexion contracture and flexion among three groups $(P<0.001)$. At the latest follow-up, the average flection-extension ROM was $(106.2 \pm 9.9)^{\circ}$ for group A, $(102.3 \pm 9.1)^{\circ}$ for group B, and $(84.1 \pm 4.9)^{\circ}$ for group C. Postoperative ROM of the three groups was different from that of each other $(P<0.001)$ (Table 2). For satisfaction levels, almost all patients were very satisfied with the outcomes and no difference was found between groups $(P=0.546)$. For the PCS and the MCS, no difference was found $(P=0.441$ and $P=0.429)$ (Table 2).

LOS for bilateral synchronous THA was $(9.8 \pm 1.6)$ days for group A, $(14.0 \pm 1.4)$ days for group B, and (16.8 \pm 7.1$)$ days for group $C$. The significant difference was found on LOS for bilateral synchronous THA between group $A$ and group $C(P=0.003)$. No difference was found between group $\mathrm{B}$ and group $\mathrm{C}(P=0.477)$ (Table 3$)$. And LOS for unilateral THA was $(9.3 \pm 3.1)$ days for group A, (11.2 \pm 3.9$)$ days for group B, and (11.5 \pm 3.7$)$ days for group $C$. The significant difference was found on LOS for group A compared with group $\mathrm{B}$ and group $\mathrm{C}(P=0.004$ and $P=0.005)$. No difference was found between group $B$ and group $\mathrm{C}(P=0.729)$ (Table 3$)$. Additionally, THE for bilateral synchronous THA was $(108,481.5 \pm 11,378.3)$ $¥$ for group A, $(126,640.5 \pm 13,609.7) ¥$ for group B, and $(109,113.8 \pm 6334.8) ¥$ for group C. No difference was 
Table 1 Perioperative demographics and component information of all included patients

\begin{tabular}{|c|c|c|c|c|}
\hline Variable & Group A & Group B & Group C & $P$ value \\
\hline \multicolumn{5}{|l|}{ Demographic characteristics } \\
\hline$M / F$ & $58 / 11$ & $38 / 2$ & $24 / 4$ & 0.342 \\
\hline$L / R$ & $54 / 40$ & $22 / 27$ & $26 / 26$ & $<0.001^{*}$ \\
\hline Age (years) & $42.2 \pm 13.8$ & $40.6 \pm 13.3$ & $38.8 \pm 8.5$ & 0.311 \\
\hline Height (cm) & $163.5 \pm 7.9$ & $165.6 \pm 7.2^{\mathrm{a}}$ & $161.0 \pm 6.7$ & $0.016^{*}$ \\
\hline Weight (kg) & $60.4 \pm 8.7$ & $61.6 \pm 8.4$ & $58.1 \pm 8.0$ & 0.155 \\
\hline $\mathrm{BMI}\left(\mathrm{kg} / \mathrm{m}^{2}\right)$ & $22.6 \pm 2.8$ & $22.4 \pm 2.4$ & $22.4 \pm 2.8$ & 0.916 \\
\hline HLA B27 positive & $58(84.1 \%)$ & $35(87.5 \%)$ & $24(85.7 \%)$ & 0.885 \\
\hline Average follow-up time (months) & $79.4 \pm 29.5$ & $80.6 \pm 28.9$ & $79.1 \pm 28.9$ & 0.966 \\
\hline Bearing surfaces (no. of hips) & & & & 0.132 \\
\hline CoC bearing & $64(68.1 \%)$ & $41(83.7 \%)$ & $37(71.2 \%)$ & \\
\hline CoP bearing & $30(31.9 \%)$ & $8(16.3 \%)$ & $15(28.8 \%)$ & \\
\hline
\end{tabular}

Values are expressed as mean \pm SD or number or number of cases (percentage)

$P$ values with statistical significance are marked with *

$M$ male, $F$ female, $L$ left, $R$ right, $B M I$ body mass index, $H L A B 27$ human leukocyte antigen B27, CoC ceramic-on-ceramic bearing, $C o P$ ceramic-on-polyethylene bearing

${ }^{\text {a }}$ Significantly different from group $C$

found among the three groups $(P=0.053)$ (Table 3$)$. THE for unilateral THA was $(54,520.4 \pm 4377.6) ¥$ for group A, $(57,353.0 \pm 3675.7) ¥$ for group B, and $(56,651.7 \pm 3861.0)$ $¥$ for group $C$. The significant difference was found on THE for group A compared to group B and C $(P<0.001$ and $P=0.020$ ) (Table 3).

\section{Radiographic evaluation}

At the latest follow-up, the average IC was $(39.5 \pm 4.6)^{\circ}$ for group A, $(39.2 \pm 4.3)^{\circ}$ for group B, and $(39.6 \pm 4.6)^{\circ}$ for group $C(P=0.882)$ (Table 4$)$. The average FO was $(4.38 \pm 0.52) \mathrm{cm}$ for group $\mathrm{A},(4.23 \pm 0.56) \mathrm{cm}$ for group $\mathrm{B}$, and $(4.26 \pm 0.52) \mathrm{cm}$ for group $\mathrm{C}(P=0.178)$ (Table 4$)$. Moreover, the average difference of bilateral FO was $(0.31 \pm 0.21) \mathrm{cm}$ for group A, $(0.32 \pm 0.18) \mathrm{cm}$ for group $\mathrm{B}$, and $(0.34 \pm 0.24) \mathrm{cm}$ for group $\mathrm{C}(P=0.794)$ (Table 4$)$. And for LLD, the average LLD was $(0.46 \pm 0.31) \mathrm{cm}$ for group $\mathrm{A},(0.44 \pm 0.34) \mathrm{cm}$ for group $\mathrm{B}$, and $(0.44 \pm 0.32)$ $\mathrm{cm}$ for group $\mathrm{C}(P=0.940)$ (Table. 4$)$. No difference was found on the IC, the FO, the difference of IC, and LLD. Figure 2 has shown the radiographs for three groups preoperatively and at the latest follow-up.

\section{Complications}

For the early-onset complications, 1 hip in group A and 1 hip in group $C$ encountered delay union of the wound. And the same patients in group $\mathrm{C}$ also encountered hip dislocation postoperatively. With effective handling, no dislocation happened evermore and the wound recovered ultimately. Additionally, one patient in group $\mathrm{C}$ encountered femur fracture intraoperatively, which was fixed with several double-loop cerclage wires immediately. The patient mainly conducted function exercises in bed until the fracture healed. For this patient, he was discharged from the hospital when he mastered the function exercises in bed. He conducted follow-up as scheduled to confirm the healing status of the fracture. For late-onset complications, 12 hips (12.8\%) in group A, 6 hips (12.2\%) in group B, and 6 hips $(11.5 \%)$ in group $C$ encountered asymptomatic $\mathrm{HO}$, all of which belonged to Brooker I or Brooker II. No significant difference was found for $\mathrm{HO}$ among the three groups $(P=0.977)$ and no influence was found for hip function. Other complications such as dislocation, osteolysis, and loosening were not observed at the latest follow-up.

\section{Discussion}

In this study, cementless THA can improve hip ROM and function for AS patients with hip involvement, while no difference was found on radiological assessment for different degrees of hip involvement. The best postoperative hip ROM after THA can be realized for non-ankylosed patients. And better postoperative hip ROM can be also found on fibrous ankylosed patients than bony ankylosed ones. Moreover, Better hip function can be obtained for non-ankylosed and fibrous ankylosed patients than bony ankylosed ones.

ROM was an essential functional outcome and could be a comprehensive reflection of THA. Because for AS patients, the disease brought them not only hips involved but also ankylosed spines. The spines have little compensation in the action of squatting. So, the increase of hip ROM can improve daily activity [6]. However, the study [6] reported that hips with preoperative bony ankylosis 
Table 2 Clinical outcomes and functional evaluation of all included patients preoperatively and at the latest follow-up

\begin{tabular}{|c|c|c|c|c|}
\hline Variable & Group A & Group B & Group C & $P$ value \\
\hline Pre-HHS & $31.5 \pm 4.3$ & $30.9 \pm 3.8$ & $30.9 \pm 5.0$ & 0.641 \\
\hline Rating (no. of hips) & & & & 0.892 \\
\hline Excellent (90-100 points) & $0(0 \%)$ & $0(0 \%)$ & $0(0 \%)$ & \\
\hline Good (80-89 points) & $0(0 \%)$ & $0(0 \%)$ & $0(0 \%)$ & \\
\hline Fair (70-79 points) & $0(0 \%)$ & $0(0 \%)$ & $0(0 \%)$ & \\
\hline Poor (<70 points) & $94(100 \%)$ & $49(100 \%)$ & $52(100 \%)$ & \\
\hline Post- HHS & $89.1 \pm 3.2^{b}$ & $88.2 \pm 3.2^{b}$ & $83.7 \pm 2.3$ & $<0.001^{*}$ \\
\hline Rating (no. of hips) & & & & $<0.001^{*}$ \\
\hline Excellent (90-100 points) & $45(47.9 \%)$ & $13(26.5 \%)$ & $0(\%)$ & \\
\hline Good (80-89 points) & 47 (50\%) & $35(71.4 \%)$ & $48(92.3 \%)$ & \\
\hline Fair (70-79 points) & $2(2.1 \%)$ & $1(2.0 \%)$ & $4(7.7 \%)$ & \\
\hline Poor (<70 points) & $0(0 \%)$ & $0(0 \%)$ & $0(0 \%)$ & \\
\hline Pre- $\mathrm{ROM}\left({ }^{\circ}\right)$ & $72.2 \pm 27.5^{a, b}$ & 0 & 0 & $<0.001^{*}$ \\
\hline Pre- flexion contracture $\left(^{\circ}\right)$ & $7.3 \pm 11.6^{a, b}$ & $23.6 \pm 20.3^{b}$ & $38.1 \pm 19.1$ & $<0.001^{*}$ \\
\hline Pre- flexion $\left(^{\circ}\right)$ & $79.5 \pm 23.8^{a, b}$ & $23.6 \pm 20.3^{b}$ & $38.1 \pm 19.0$ & $<0.001^{*}$ \\
\hline Post- ROM $\left(^{\circ}\right)$ & $106.2 \pm 9.9^{a, b}$ & $102.3 \pm 9.1^{b}$ & $84.1 \pm 4.9$ & $<0.001^{*}$ \\
\hline Post- flexion contracture $\left(^{\circ}\right)$ & $0.8 \pm 2.2$ & $0.9 \pm 2.4$ & $1.3 \pm 3.1$ & 0.457 \\
\hline Post- flexion $\left(^{\circ}\right)$ & $106.9 \pm 9.5^{a, b}$ & $103.3 \pm 8.7^{b}$ & $85.5 \pm 4.7$ & $<0.001^{*}$ \\
\hline Post- abduction $\left({ }^{\circ}\right)$ & $33.7 \pm 3.6$ & $33.5 \pm 4.4$ & $32.6 \pm 4.0$ & 0.244 \\
\hline Satisfication level & & & & 0.546 \\
\hline Very satisfied & $80(96.4 \%)$ & $45(95.7 \%)$ & $39(97.5 \%)$ & \\
\hline Satisfied & $3(3.6 \%)$ & $2(4.3 \%)$ & $1(2.5 \%)$ & \\
\hline Somewhat unsatisfied & $0(0 \%)$ & $0(0 \%)$ & $0(0 \%)$ & \\
\hline Unsatisfied & $0(\%)$ & $0(\%)$ & $0(\%)$ & \\
\hline \multicolumn{5}{|l|}{ SF-12 } \\
\hline PCS & $22.1 \pm 1.8$ & $22.1 \pm 1.8$ & $21.6 \pm 2.3$ & 0.441 \\
\hline MCS & $25.4 \pm 2.1$ & $24.9 \pm 2.2$ & $25.0 \pm 1.9$ & 0.429 \\
\hline
\end{tabular}

Values are expressed as mean \pm SD

$P$ values with statistical significance are marked with *

Pre- preoperative, Post- postoperative, HHS Harris hip score, ROM range of motion, $P C S$ physical component summary, MCS mental component summary

${ }^{\text {a }}$ Significantly different from group $B$

${ }^{\mathrm{b}}$ Significantly different from group $\mathrm{C}$

Table 3 Length of stay and total hospital expense of all included patients

\begin{tabular}{|c|c|c|c|c|}
\hline Variable & Group A & Group B & Group C & $P$ value \\
\hline \multicolumn{5}{|l|}{ LOS } \\
\hline LOS for bilateral synchronous procedure (d) & $9.8 \pm 1.6^{b}$ & $14.0 \pm 1.4$ & $16.8 \pm 7.1$ & $0.012^{*}$ \\
\hline LOS for unilateral procedure (d) & $9.3 \pm 3.1^{a, b}$ & $11.2 \pm 3.9$ & $11.5 \pm 3.7$ & $0.003^{*}$ \\
\hline \multicolumn{5}{|l|}{ THE } \\
\hline THE for bilateral synchronous procedure ( $¥)$ & $108,481.5 \pm 11,378.3$ & $126,640.5 \pm 13,609.7$ & $109,113.8 \pm 6334.8$ & 0.053 \\
\hline THE for unilateral procedure ( $¥)$ & $54,520.4 \pm 4377.6^{a, b}$ & $57,353.0 \pm 3675.7$ & $56,651.7 \pm 3861.0$ & $0.001^{*}$ \\
\hline
\end{tabular}

Values are expressed as mean $\pm S D$

$P$ values with statistical significance are marked with *

LOS, length of stay; THE, total hospital expense

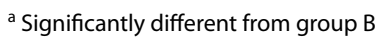

${ }^{b}$ Significantly different from group $C$ 
Table 4 radiographic evaluation of all included patients between groups postoperatively

\begin{tabular}{lllll}
\hline Variable & Group A & Group B & Group C & P value \\
\hline Average IC $\left(^{\circ}\right)$ & $39.5 \pm 4.6$ & $39.2 \pm 4.3$ & $39.6 \pm 4.6$ & 0.882 \\
Average FO $(\mathrm{cm})$ & $4.38 \pm 0.52$ & $4.23 \pm 0.56$ & $4.26 \pm 0.52$ & 0.178 \\
$\begin{array}{l}\text { The difference of } \\
\text { bilateral FO }(\mathrm{cm})\end{array}$ & $0.31 \pm 0.21$ & $0.32 \pm 0.18$ & $0.34 \pm 0.24$ & 0.794 \\
LLD $(\mathrm{cm})$ & $0.46 \pm 0.31$ & $0.44 \pm 0.34$ & $0.44 \pm 0.32$ & 0.940 \\
\hline
\end{tabular}

Values are expressed as mean \pm SD

$P$ values with statistical significance are marked with *

IC inclination of cup, FO femoral offset, LLD leg length discrepancy

would result in poorer postoperative ROM compared with those stiff cases. Also, our study found that different ROM improvements were realized among the three groups and the non-ankylosed hips obtained the best ROM after THA. We speculate that the soft tissue and muscles of the ankylosed hip were less-quality and weaker than that of non-ankylosed and fibrous hips due to long-term stiffness. This may result in different restoration of ROM after THA. SF-12 score including PCS and MCS was a generic health rating scale to evaluate the physical and mental health of patients [26]. And satisfaction levels reflected the clinical outcome of THA for AS patients. Lu et al. [27] have reported that the improvements in hip function and self-care ability after THA were the decisive factors in determining patient satisfaction for patients with ankylosed hips secondary to AS. But for non-ankylosed hips with some degree of mobility, pain relief and restoration of walking ability had more influence on satisfaction levels [28, 29]. And no matter non-ankylosed hips or ankylosed hips, THA can solve
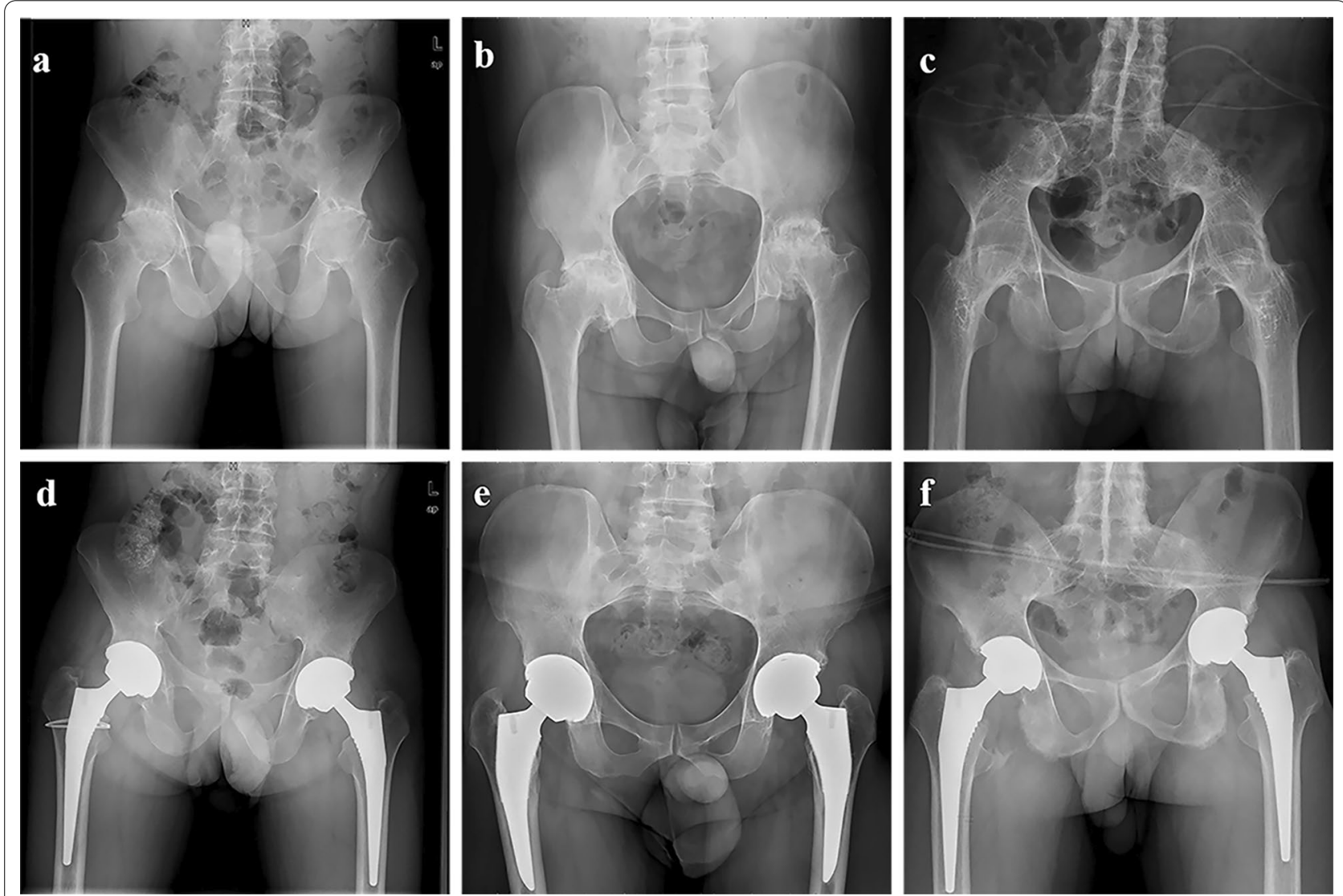

Fig. 2 Case presentation of bilateral cementless bilateral total hip arthroplasty for three different degrees of hips involvement with ankylosing spondylitis. a The radiograph showed bilateral hips involved preoperatively and physical examination showed no total loss of range of motion. $\mathbf{b}$ The radiograph showed bilateral hips involved and no trabecula bridged the hip joint plane preoperatively and physical examination showed total loss of range of motion. $\mathbf{c}$ The radiograph showed bilateral hips involved and trabecula bridged the hip joint plane preoperatively and physical examination showed total loss of range of motion. $\mathbf{d}$ The pelvis radiograph at the latest follow-up (78 months for both hips) for Fig. 1a showed excellent prosthesis position, no loosening and migration of the component. e The pelvis radiograph at the latest follow-up (82 months for right hip and 81 months for left hip) for Fig. 1b showed excellent prosthesis position, no loosening and migration of the component. fThe pelvis radiograph at the latest follow-up (80 months for both hips) for Fig. 1c showed excellent prosthesis position, no loosening and migration of the component 
the problems. So, THA can realize a similar satisfaction level and SF-12 score according to our result. LOS was the first driver of cost after primary total joint arthroplasty and strategies to decrease LOS may help reduce the economic burden [30]. The increased operation time was independently associated with increased costs [31]. THA for ankylosed hip needed longer operation time and caused more surgical trauma, which may result in longer LOS and more cost. From the comparison of the nonankylosed group with the ankylosed group, we indeed found that the less severe degree of hip involvement, the less LOS and cost were spent.

According to Pregash et al. [19], the clinical outcome of THA correlated with FO reconstruction, which was related to hip abductor strength and LLD. AS was pathologically characterized by the inflammation of tendon insertion leading to bony deformity, soft-tissue contracture, and disused weakness of abductor muscles [2, 13]. So, for AS patients, restoration of FO closed to normality and minimized LLD was crucial to good clinical outcomes. FO defined as the perpendicular distance from the center of the femoral head to the axis of the femur [32] indicated the tension of hip abductor muscles [19]. FO reconstruction can realize adequate joint stability, avoid bony and soft-tissue impingement [33, 34], and obtain the lowest liner wear as well as the least gait alteration [35]. Also, Little et al. [35] also suggested that the offset difference was also significant. They recommended [35] that if the offset difference exceeded $5 \mathrm{~mm}$, the liner wear would accelerate. Although there were different surgical difficulties for the three groups, the average FO was similar. And the average FO difference was $3 \mathrm{~mm}$ and less than the reported $5 \mathrm{~mm}$ [35] for the three groups. So, for AS patients included, all hips have realized small FO differences regardless of the degrees of involvement.

LLD was also crucial for AS patients. Upadhyay et al. [36] reported that LLD was the second most common complaint from patients who were performed THA and about $8 \%$ of surgeons experienced litigation secondary to LLD. Postoperative LLD would increase frontal plane tilt angle of the pelvis and plane motion of the pelvis during walking [37] and lead to pelvis obliquity [38], gait abnormalities [39, 40], lower back pain [41], and functional disturbance of adjacent joints [42]. Besides, LLD exceeding $20 \mathrm{~mm}$ increased oxygen consumption [43] and LLD exceeding $10 \mathrm{~mm}$ increased the risk of aseptic loosening $[38,42]$. For unequal leg length, the longer limb occupied $39 \%$ of the load while the shorter limb occupied $65 \%$ of the load in the static phase [44] and the bigger load for the shorter limb in the dynamic phase [45]. For AS patients, they were usually younger, more active, had higher demand for gait improvement, and cared more about the long-term survival of prostheses.
So, the ambition was to realize equal limb length when performing THA for AS patients. Moreover, the detailed preoperative project and repeated confirmation intraoperatively were conducive to less LLD. As for our results, the average LLD for the three groups was not more than $0.5 \mathrm{~cm}$ and less than the reported $1 \mathrm{~cm}[38,42]$. And no difference was found among the three groups.

The study reported that AS patients showed a higher rate of perioperative and postoperative complications after THA including wound complication, polyethylene wear, revision, and dislocation [46]. Survival analysis of THA for AS was $81.4 \%$ at 15 years [4], which was lower than that of THA for other etiologies [47]. Also, the rate of polyethylene wear of THA for the bony ankylosed hip was high than that of primary THA concluded by Kim et al. [48]. Because the AS patients receiving THA were usually younger and more active. They had a high demand for hip function and the activity level was also higher than patients with osteoarthritis [46]. Additionally, AS was characterized by the spine and hip joint involved. The patients were usually accompanied with abnormal spinopelvic mechanics leading to abnormal stress to the implants and abnormal positions of the pelvis for AS patients increasing the difficulties of inserting the prosthesis in ideal positions [10, 49]. So, more activity and possibly suboptimal component position can account for the higher postoperative complications. HO was another complication encountered after THA for AS patients but was symptomatic in a minority of patients [50]. According to the published literature, $10.5 \%$ of patients developed HO consistent with Brooker I or II and no reports of re-ankylosis [51]. And nearly $12 \%$ of patients with ankylosed hips may encounter $\mathrm{HO}$ belonging to Brooker I [52]. The incidence of $\mathrm{HO}$ in our study was nearly $12 \%$ and classified as Brooker I or II. And no influence was found on hip function. This was similar to the published result.

We noted some limitations of the study. This was a retrospective study in a single joint center with the unavoidable weakness inherently. But the study was the currently biggest sample-size research on the outcomes of THA for hip involved secondary to AS. Also, we firstly compared the effectiveness of THA for three different degrees of hip involvement. The surgery-specific information including perioperative blood loss, surgery time, and inflammatory response to surgical trauma can't be obtained. However, with the fast development of enhanced recovery after surgery, the blood loss, traumatic response, and surgical time can be lesser and lesser. At last, we can't give accurate information about the AS duration and symptom duration. Because most of the included patients were not treated in our hospital before surgery. And we can't obtain accurate preoperative information. 


\section{Conclusion}

For AS patients with three different degrees of hip involvement, THA can improve hip ROM and enhance hip function. The better hip ROM and clinical outcomes postoperatively can be realized for the nonankylosed hips than ankylosed ones with relatively less cost and LOS.

\begin{abstract}
Abbreviations
AS: Ankylosing spondylitis; ROM: Range of motion; THA: Total hip arthroplasty; HHS: Harris hip score; SF-12: The short-form 12 health survey; LOS: Length of stay; THE: Total hospital expense; LLD: Leg length discrepancy; HO: Heterotopic ossification; PCS: Physical component summary; MCS: Mental component summary; IC: Inclination of cup; FO: Femoral offset; ANOVA: A 1-way analysis of variance; HLA B27: Human leukocyte antigen B27; CoC: Ceramic-on-ceramic; CoP: Ceramic-on-polyethylene.
\end{abstract}

\section{Acknowledgements}

We thank all the patients for their participation in our study, and we are grateful to the staff of our department for their support and contribution to this study. All authors declare that they have no financial or personal relationships with other people or organizations that might inappropriately influence this study.

\section{Authors' contributions}

ZKZ conceived and designed this study; AJC, ZJ, and XYD collected the data; PM wrote the manuscript; $\mathrm{HL}$ and AJC performed the statistical analysis, PM, $\mathrm{HL}$, and $\mathrm{AJC}$ prepared tables. PM and $\mathrm{HL}$ prepared pictures. PM, HL, and ZKZ revised this manuscript. All authors reviewed the final manuscript. All authors agreed to be accountable for all aspects of the work. PM and HL contributed equally to this work and should be considered as equal first authors. All authors read and approved the final manuscript.

\section{Funding}

This research was funded by Regional Innovation \& Cooperation program of Science \& Technology Department of Sichuan Province (grant number: 2021YFQ0028), Key Research \& Development program of Science \& Technology Department of Sichuan Province (grant number: 2021YFS0167), and 1, 3, 5 project for disciplines of excellence, West China Hospital, Sichuan University (grant number: ZYJC18039).

\section{Availability of data and materials}

The datasets used and/or analyzed during the current study are available from the corresponding author on reasonable request.

\section{Declarations}

\section{Ethics approval and consent to participate}

This study has been approved by the Clinical Trials and Biomedical Ethics Committee of West China Hospital, Sichuan University. All related datasets were permitted to access and use. All experiments were performed in accordance with relevant guidelines and regulations. This study was conducted in accordance with the Declaration of Helsinki.

\section{Consent for publication}

All data collected in this study have consent for publication.

\section{Competing interests}

The authors announced that they did not have any competing interests.

\section{Author details}

1 Department of Orthopedics, Orthopedic Research Institute, West China Hospital, Sichuan University, \#37 Guoxue Road, Chengdu 610041, People's Republic of China. ${ }^{2}$ Department of Rehabilitation Medicine, Jiang You Second People's Hospital, \#10 Tuanshan Road, Jiang you 621702, People's Republic of China. ${ }^{3}$ West China School of Nursing, Sichuan University, Chengdu 610041, People's Republic of China.

Received: 27 June 2021 Accepted: 21 September 2021

Published online: 16 October 2021

\section{References}

1. van der Linden S, Valkenburg HA, Cats A. Evaluation of diagnostic criteria for ankylosing spondylitis. A proposal for modification of the New York criteria. Arthritis Rheum. 1984;27(4):361-8.

2. Braun J, Sieper J. Ankylosing spondylitis. Lancet. 2007;369(9570):1379-90.

3. Xiang YJ, Dai SM. Prevalence of rheumatic diseases and disability in China. Rheumatol Int. 2009;29(5):481-90.

4. Joshi AB, Markovic L, Hardinge K, Murphy JC. Total hip arthroplasty in ankylosing spondylitis: an analysis of 181 hips. J Arthroplast. 2002:17(4):427-33.

5. Gautam D, Malhotra R. Total hip arthroplasty in ankylosing spondylitis with extension contracture of hips. J Arthroplast. 2019;34(1):71-6.

6. Li J, Xu W, Xu L, Liang Z. Hip resurfacing arthroplasty for ankylosing spondylitis. J Arthroplast. 2009;24(8):1285-91.

7. Jordan CL, Rhon DI. Differential diagnosis and management of ankylosing spondylitis masked as adhesive capsulitis: a resident's case problem. J Orthop Sports Phys Ther. 2012:42(10):842-52.

8. Reveille JD. Epidemiology of spondyloarthritis in North America. Am J Med Sci. 2011:341(4):284-6.

9. Tang WM, Chiu KY. Primary total hip arthroplasty in patients with ankylosing spondylitis. J Arthroplast. 2000;15(1):52-8.

10. Wang W, Huang G, Huang T, Wu R. Bilaterally primary cementless total hip arthroplasty in patients with ankylosing spondylitis. BMC Musculoskelet Disord. 2014;15:344

11. Kim YL, Shin SI, Nam KW, Yoo JJ, Kim YM, Kim HJ. Total hip arthroplasty for bilaterally ankylosed hips. J Arthroplast. 2007;22(7):1037-41.

12. Wu H, Cheng WD, Jing J. Total hip arthroplasty by direct anterior approach in the lateral position for the treatment of ankylosed hips. Eur J Orthop Surg Traumatol. 2020;30(6):993-1001.

13. Zhang $L$, Yang D, Yin $X$, Zhou Y. Risk factors for poor hip flexion after total hip arthroplasty for the treatment of ankylosing spondylitis a multivariate analysis. Clin Rheumatol. 2014;33(9):1295-301.

14. Bangjian H, Peijian T, Ju L. Bilateral synchronous total hip arthroplasty for ankylosed hips. Int Orthop. 2012;36(4):697-701.

15. Kim YH, Oh SH, Kim JS, Lee SH. Total hip arthroplasty for the treatment of osseous ankylosed hips. Clin Orthop Relat Res. 2003:414:136-48.

16. Hamadouche M, Kerboull L, Meunier A, Courpied JP, Kerboull M. Total hip arthroplasty for the treatment of ankylosed hips: a five to twenty-oneyear follow-up study. J Bone Joint Surg Am. 2001;83(7):992-8.

17. Harris WH. Traumatic arthritis of the hip after dislocation and acetabular fractures: treatment by mold arthroplasty. An end-result study using a new method of result evaluation. J Bone Joint Surg Am. 1969;51(4):737-55.

18. Wang D, Li LL, Wang HY, Pei FX, Zhou ZK. Long-term results of cementless total hip arthroplasty with subtrochanteric shortening osteotomy in crowe type IV developmental dysplasia. J Arthroplast. 2017;32(4):1211-9.

19. Ellapparadja P, Mahajan V, Deakin AH, Deep K. Reproduction of hip offset and leg length in navigated total hip arthroplasty: How accurate are we? J Arthroplast. 2015;30(6):1002-7.

20. Keršič M, Dolinar D, Antolič V, Mavčič B. The impact of leg length discrepancy on clinical outcome of total hip arthroplasty: comparison of four measurement methods. J Arthroplast. 2014;29(1):137-41.

21. Brooker AF, Bowerman JW, Robinson RA, Riley LH Jr. Ectopic ossification following total hip replacement. Incidence and a method of classification. J Bone Joint Surg Am. 1973;55(8):1629-32.

22. Joshi RP, Eftekhar NS, McMahon DJ, Nercessian OA. Osteolysis after Charnley primary low-friction arthroplasty. A comparison of two matched paired groups. J Bone Joint Surg Br. 1998;80(4):585-90.

23. Maloney WJ, Jasty M, Harris WH, Galante JO, Callaghan JJ. Endosteal erosion in association with stable uncemented femoral components. J Bone Joint Surg Am. 1990;72(7):1025-34. 
24. DeLee JG, Charnley J. Radiological demarcation of cemented sockets in total hip replacement. Clin Orthop Relat Res. 1976;121:20-32.

25. Engh CA, Massin P, Suthers KE. Roentgenographic assessment of the biologic fixation of porous-surfaced femoral components. Clin Orthop Relat Res. 1990;257:107-28.

26. Ware J Jr, Kosinski M, Keller SD. A 12-item short-form health survey: construction of scales and preliminary tests of reliability and validity. Med Care. 1996;34(3):220-33.

27. Ding L, Gao YH, Li YR, Liu JG, Li SQ, Qi X. Determinants of satisfaction following total hip arthroplasty in patients with ankylosing spondylitis. Int Orthop. 2018;42(3):507-11.

28. Brokelman RB, van Loon CJ, Rijnberg WJ. Patient versus surgeon satisfaction after total hip arthroplasty. J Bone Joint Surg Br. 2003;85(4):495-8.

29. Espehaug B, Havelin LI, Engesaeter LB, Langeland N, Vollset SE. Patient satisfaction and function after primary and revision total hip replacement. Clin Orthop Relat Res. 1998;351:135-48.

30. Olthof M, Stevens M, Bulstra SK, van den Akker-Scheek I. The association between comorbidity and length of hospital stay and costs in total hip arthroplasty patients: a systematic review. J Arthroplast. 2014:29(5):1009-14

31. Peel TN, Cheng AC, Liew D, et al. Direct hospital cost determinants following hip and knee arthroplasty. Arthritis Care Res (Hoboken). 2015;67(6):782-90.

32. Dastane M, Dorr LD, Tarwala R, Wan Z. Hip offset in total hip arthroplasty: quantitative measurement with navigation. Clin Orthop Relat Res. 2011;469(2):429-36

33. McGrory BJ, Morrey BF, Cahalan TD, An KN, Cabanela ME. Effect of femoral offset on range of motion and abductor muscle strength after total hip arthroplasty. J Bone Joint Surg Br. 1995;77(6):865-9.

34. Matsushita A, Nakashima Y, Jingushi S, Yamamoto T, Kuraoka A, Iwamoto $Y$. Effects of the femoral offset and the head size on the safe range of motion in total hip arthroplasty. J Arthroplast. 2009;24(4):646-51.

35. Little NJ, Busch CA, Gallagher JA, Rorabeck CH, Bourne RB. Acetabular polyethylene wear and acetabular inclination and femoral offset. Clin Orthop Relat Res. 2009;467(11):2895-900.

36. Upadhyay A, York S, Macaulay W, McGrory B, Robbennolt J, Bal BS. Medical malpractice in hip and knee arthroplasty. J Arthroplast. 2007;22(6 Suppl 2):2-7.

37. Bolink $S$, Lenguerrand $E$, Brunton LR, et al. The association of leg length and offset reconstruction after total hip arthroplasty with clinical outcomes. Clin Biomech (Bristol, Avon). 2019;68:89-95.

38. Della Valle CJ, Di Cesare PE. Complications of total hip arthroplasty: neurovascular injury, leg-length discrepancy, and instability. Bull Hosp Jt Dis. 2001:60(3-4):134-42.
39. Benedetti MG, Catani F, Benedetti E, Berti L, Di Gioia A, Giannini S. To what extent does leg length discrepancy impair motor activity in patients after total hip arthroplasty? Int Orthop. 2010;34(8):1115-21.

40. Lai KA, Lin CJ, Jou IM, Su FC. Gait analysis after total hip arthroplasty with leg-length equalization in women with unilateral congenital complete dislocation of the hip-comparison with untreated patients. J Orthop Res. 2001;19(6):1147-52.

41. Nichols PJ. Short-leg syndrome. Br Med J. 1960;1(5189):1863-5.

42. Kaufman KR, Miller LS, Sutherland DH. Gait asymmetry in patients with limb-length inequality. J Pediatr Orthop. 1996;16(2):144-50.

43. Gurney B, Mermier C, Robergs R, Gibson A, Rivero D. Effects of limblength discrepancy on gait economy and lower-extremity muscle activity in older adults. J Bone Joint Surg Am. 2001;83(6):907-15.

44. Swaminathan V, Cartwright-Terry M, Moorehead JD, Bowey A, Scott SJ. The effect of leg length discrepancy upon load distribution in the static phase (standing). Gait Posture. 2014;40(4):561-3.

45. White SC, Gilchrist LA, Wilk BE. Asymmetric limb loading with true or simulated leg-length differences. Clin Orthop Relat Res. 2004;421:287-92.

46. Blizzard DJ, Penrose CT, Sheets CZ, Seyler TM, Bolognesi MP, Brown CR. Ankylosing spondylitis increases perioperative and postoperative complications after total hip arthroplasty. J Arthroplast. 2017;32(8):2474-9.

47. Sodhi N, Mont MA. Survival of total hip replacements. Lancet. 2019:393(10172):613.

48. Kim YH, Kim JS, Cho SH. Primary total hip arthroplasty with a cementless porous-coated anatomic total hip prosthesis: 10- to 12-year results of prospective and consecutive series. J Arthroplast. 1999;14(5):538-48.

49. Zheng GQ, Zhang YG, Chen JY, Wang Y. Decision making regarding spinal osteotomy and total hip replacement for ankylosing spondylitis: experience with 28 patients. Bone Joint J. 2014;96-b(3):360-5.

50. Board TN, Karva A, Board RE, Gambhir AK, Porter ML. The prophylaxis and treatment of heterotopic ossification following lower limb arthroplasty. J Bone Joint Surg Br. 2007;89(4):434-40.

51. Lin D, Charalambous A, Hanna SA. Bilateral total hip arthroplasty in ankylosing spondylitis: a systematic review. EFORT Open Rev. 2019;4(7):476-81.

52. Mou P, Zeng WN, Chen Y, Zhou Z. Synchronous or sequential cementless bilateral total hip arthroplasty for osseous ankylosed hips with ankylosing spondylitis. BMC Musculoskelet Disord. 2021;22(1):302.

\section{Publisher's Note}

Springer Nature remains neutral with regard to jurisdictional claims in published maps and institutional affiliations.
Ready to submit your research? Choose BMC and benefit from:

- fast, convenient online submission

- thorough peer review by experienced researchers in your field

- rapid publication on acceptance

- support for research data, including large and complex data types

- gold Open Access which fosters wider collaboration and increased citations

- maximum visibility for your research: over 100M website views per year

At $B M C$, research is always in progress.

Learn more biomedcentral.com/submissions 